\title{
INFOGRAFIA E EDUCAÇÃO: PROPOSTA DE PROCESSO DE DESIGN PARA INFOGRÁFICOS NA EDUCAÇÃO À DISTÂNCIA
}

Bolívar Teston de Escobar ${ }^{1}$

Universidade Federal do Paraná

Carla Galvão Spinillo²

Universidade Federal do Paraná

Resumo: O presente artigo apresenta uma proposta de design de infográficos como conteúdo didático para educação à distância. Através de levantamento bibliográfico, os conceitos de infografia, processos de design e educação à distância são apresentados e, a partir deles, requisitos para a proposta de processo de design são sugeridos e sua configuração é visualizada.

Palavras-chave: infografia, processo de design, educação à distância.

Abstract: This paper presents a proposal of a design process for educational infographics in the context of the distance learning. A bibliographic review takes place in order to explain the concepts of infographics, design process and distance learning. The proposed design process is, then, visualized.

Keywords: infographics, design process, distance learning. 


\section{INTRODUÇÃO}

A elaboração de infográficos é resultado de um processo de design cujas etapas envolvem um alto grau de multidisciplinaridade: as etapas iniciais centram-se na pesquisa e produção do conteúdo, passando pela síntese e transformação deste em elementos pictóricos e esquemáticos que são então diagramados e organizados em uma peça cujas características, de acordo com Lima (2015), incluem sua configuração diagramática e a não-linearidade da leitura. É, portanto, objetivo deste processo produzir uma apresentação mais acessível, compreensível e linguisticamente próxima desse conteúdo para o público-alvo.

O objetivo do presente artigo é discutir a possibilidade de aplicação dos materiais infográficos no meio educacional - mais precisamente, nos materiais didáticos utilizados em cursos de educação à distância. Propõe-se um levantamento dos processos de design de infográficos e uma possível adaptação para o contexto da educação à distância. Dado o entendimento de sua origem como sendo o meio jornalístico (Moares, 2013), visa-se, através deste estudo, propor a igualmente eficaz aplicação da infografia no meio educativo.

O artigo configura-se, portanto, como resultado de uma pesquisa aplicada, conforme Marconi e Lakatos (1999) e descritiva segundo Gil (2002) já que, em seu decorrer, apresenta características que fundamentam os conceitos de educação à distância, infografia e dos desdobramentos resultantes da intersecção desses dois temas através de levantamento bibliográfico.

Obtém-se, concluindo, uma proposta de processo de design baseada em requisitos obtidos de outros processos similares e da configuração da produção de saberes dentro do contexto da educação à distância.

\section{PROCESSO DE DESIGN NA INFOGRAFIA}

Miranda (2013) menciona o termo "infográfico" como uma tradução do espanhol infografía, que por sua vez veio do original inglês infographics, uma aglutinação das palavras "information" e "graphics". O conceito passou a ser empregado no jornalismo quando materiais que combinavam imagens, textos e ícones na mesma peça eram empregados para ancorar o texto com explicações mais precisas de elementos complexos dentro da narrativa (Moraes, 2013).

\subsection{Breve histórico e definição da infografia}

Enquanto no Brasil a infografia começou a se fortalecer por volta dos anos 80 (Moraes, 2013), a técnica do emprego misto de elementos pictóricos, verbais e esquemáticos para a criação de peças gráficas é antiga e teve aplicações variadas ao longo do tempo (Rajamanickan, 2005). Um dos primeiros exemplos é o gráfico de Florence Nightingale (1820-1910), cujo objetivo era demonstrar visualmente os efeitos das más condições de higiene dos hospitais durante a Guerra da Criméia (figura 1). 


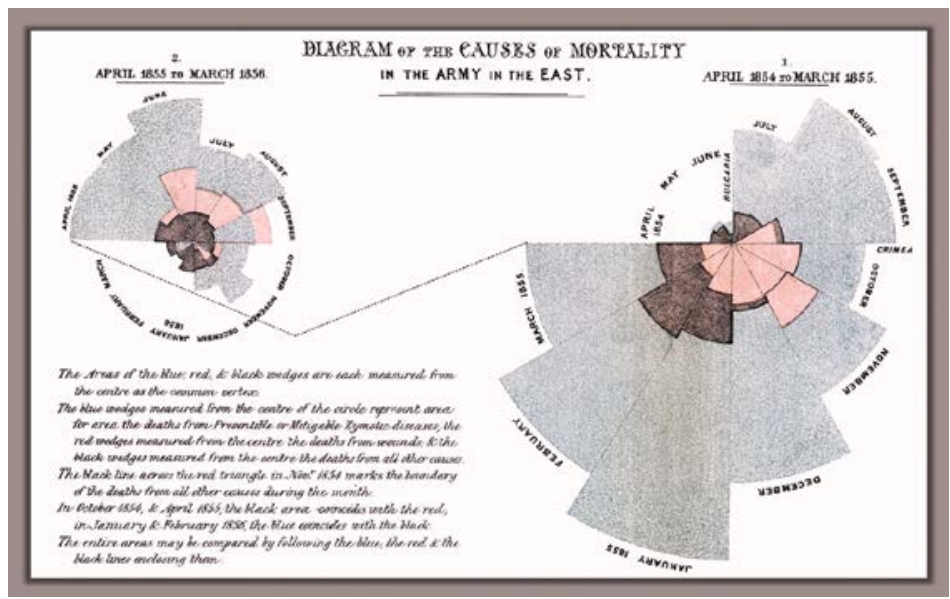

Figura 1 - Gráfico de Nightingale (conhecido como "coxcomb"), comparando o número de mortes e as causas (Fonte: domínio público).

Moraes comenta que a infografia foi ganhando nome como modalidade dentro do design conforme novas tecnologias eram empregadas na concepção de peças gráficas (Moraes, 2013). Entretanto, qualquer esforço gráfico para elucidar conceitos complexos correspondia às características da infografia conforme postas por Lima (2015):

\footnotetext{
"A infografia pode ser vista como uma evolução do diagrama tradicional, pois possui as mesmas características básicas de um diagrama. Ao contrário do texto linear tradicional, utiliza diferentes recursos gráficos e possui uma estrutura que oferece uma estratégia de leitura nãolinear, permitindo que o leitor escolha o encadeamento da narrativa." (LIMA, 2015:121)
}

Dentro da área da saúde, por exemplo, é possível citar Leonardo da Vinci (1452-1519) e seus manuscritos (figura 2) como um exemplo clássico de diagrama informativo. Através deles, o autor passava ao leitor uma possibilidade maior de compreensão de alguns conceitos anatômicos que, na época, eram de difícil acesso.

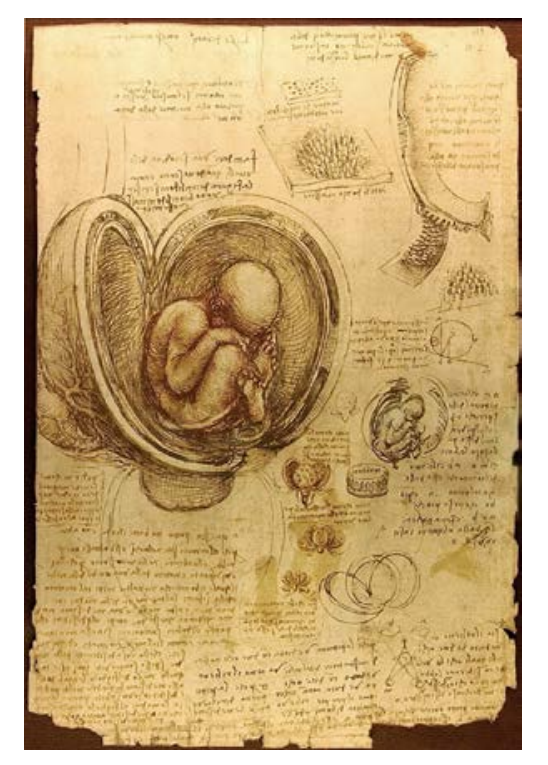

Figura 2 - Estudos do feto no útero por Leonardo Da Vinci em manuscrito concebido por volta de 1510-1512 Fonte: Geneva Foundation for Medical Education and Research (2006). 
Quanto a classificação dos infográficos, Moraes (2013) propõe a seguinte nomenclatura baseada no propósito do infográfico:

- Infográficos exploratórios: respondem às perguntas o quê?, quem? ou ainda onde?

- Infográficos explanatórios: respondem às perguntas como? Ou por quê?

- Infográficos historiográficos: responde às perguntas quando?

Além da abrangência temática, a infografia, por seu caráter multimidiático, também compreende o uso de canais e tecnologias disponíveis para melhor traduzir conceitos. Miranda (2013) defende que infográficos são capazes de ser apresentados como vídeos ou como ferramentas interativas, proporcionando mais vieses denominativos para o seu escopo como peça gráfica. Justamente por esse grande potencial comunicativo, a infografia parte do jornalismo para apresentar-se como recurso dentro da ciência como ferramenta de divulgação. Segundo Schmitt (2006), o infografista é o profissional ideal para comunicar conceitos científicos, já que trabalha com três ferramentas necessárias para tornais tais mensagens compreensíveis: a abstração, a metáfora e a interatividade.

\subsection{Processo de design}

Existem diferentes abordagens quanto à criação de infográficos. Definidos como materiais pertencentes ao campo do design da informação (Andrade, 2014), tem-se como definição de seu processo de criação um processo, portanto, de design.

O processo de design, conforme sua definição mais básica de acordo com a CBD (Centro Brasil Design) consiste de cinco etapas: preparação; conceituação; desenvolvimento; testes; e implementação. Essas etapas são encontradas em várias configurações de processos de design, como no exemplo do Double Diamond, definido pelo Design Council (2007) como uma progressão linear que parte da descoberta, passa pela definição, depois pelo desenvolvimento e, no fim, pela entrega.

Segundo o PMI (Project Management Institute), cabe ao gestor a decisão sobre quais etapas levam mais tempo, ou até mesmo sobre quais precisam ser ramificadas em procedimentos mais minuciosos ou até mesmo eliminadas do escopo do projeto (PMBOK, 2000). A gestão do projeto prevê, portanto, a possibilidade de adequação do processo de design em relação ao objetivo.

De acordo com Frascara (2004), é comum aos projetos de design uma preocupação comunicativa centrada em três grandes áreas:

- Clareza (de forma e função): ênfase na apresentação e organização dos elementos formais;

- Facilidade e estímulo da leitura;

- Consideração dos aspectos culturais, econômicos e sociais do contexto no qual se desenvolve o projeto.

O projeto é, sendo guiado por tais diretrizes, disposto ao longo de etapas dentro de um processo composto de dez etapas:

1. Encomenda: onde define-se o problema e o escopo orçamentário;

2. Primeira coleta de informações: sobre o cliente, empresa e públicoalvo; 
3. Segunda definição de problema: onde analisa-se as informações coletadas no item 2;

4. Definição de objetivos: definição da forma, canais de comunicação, entendimentos iniciais da implementação;

5. Terceira definição do problema: onde o briefing do design é elaborado, com especificações sobre o produto almejado;

6. Desenvolvimento: onde são elaborados as considerações sobre a forma, conteúdo e tecnologia;

7. Apresentação ao cliente;

8. Organização da produção: onde prepara-se o design final;

9. Supervisão da implementação;

10. Avaliação da performance: onde compara-se o resultado final com os objetivos iniciais.

Percebe-se, ao percorrer os itens propostos por Frascara em seu processo, uma grande preocupação principalmente com a definição clara do problema e com a avaliação final do cumprimento dos objetivos do design. Tais etapas - problematização e validação - são uma constante também em processos de design que optam por centrar o usuário como elemento nuclear do projeto. De acordo com Goodwin (2009), quando centrado no usuário, o design transforma-se no ofício de visualizar soluções concretas que atendem metas humanas pré-estabelecidas pelo contexto. Justamente por causa desses modificadores como usuário e contexto, o processo de design pode se configurar diferentemente como linear, iterativo, holístico ou como "estrela", sendo tais configurações a forma como os procedimentos dispõem-se em sequencia (Rocha \& Baranauskas, 2003).

Quando tratado como pertencente à linguagem gráfica (Twyman, 1979), o design gráfico incorpora em seus processos a necessidade da articulação dos símbolos e sinais linguísticos. Baseado nisso, na figura 3 Spinillo (2000) propõe um processo de design que considera etapas de pré e pós-design, nas quais são consideradas as necessidades cognitivas dos usuários de produtos editoriais:

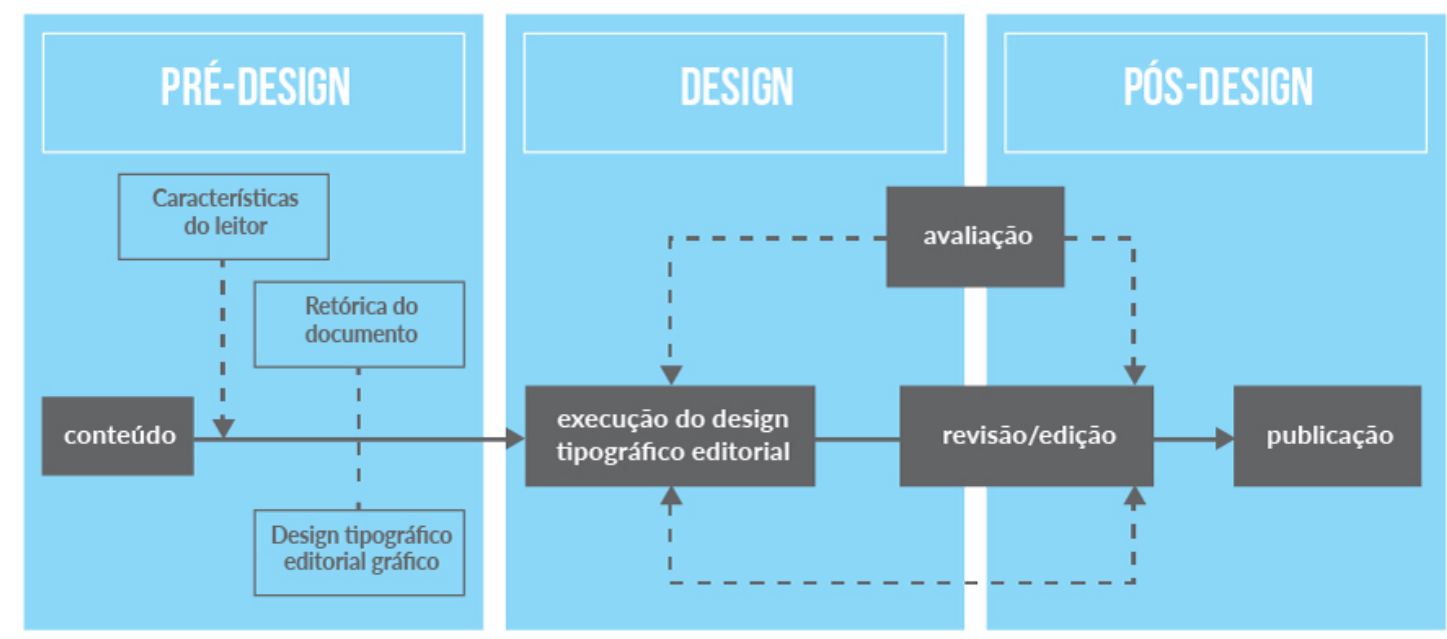

Figura 3 - Processo de design editorial de Spinillo (2000) baseado em Felker \& Rose (1989) - adaptado pelo autor. 
No exemplo anterior, o processo de design começa a se aproximar dos requisitos da infografia ao considerar a retórica do documento e a natureza tipográfica editorial da peça. Conforme Aragão \& Carvalho (2012), o infográfico segue um padrão editorial de publicação e o processo envolve etapas de análises de referência. Segundo os autores, o processo da infografia compreende três grandes etapas - concepção, execução e acabamento - que se desdobram na seguinte metodologia linear representada na figura 4 :

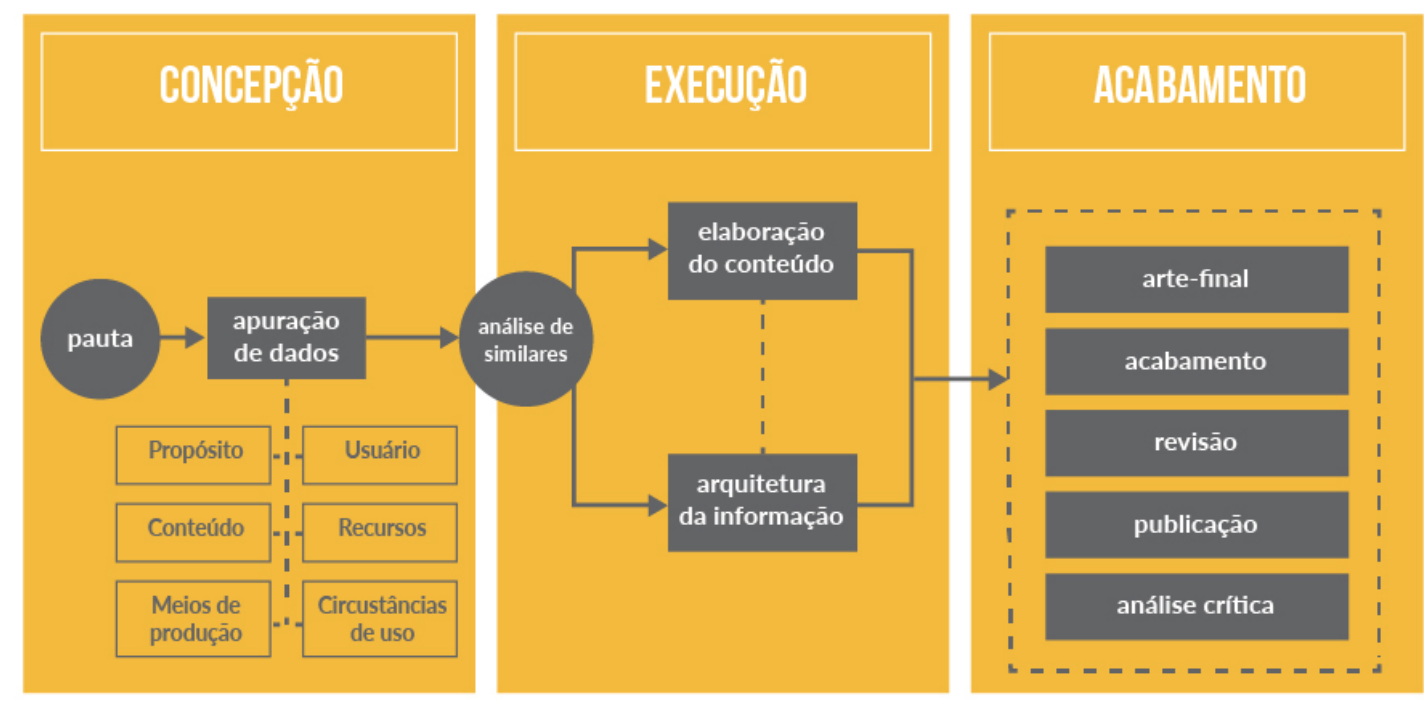

Figura 4 - Processo de design de infográficos segundo Aragão e Carvalho (2012) - adaptado pelo autor.

Moraes (2013) expõe o processo a partir da concepção do infográfico como uma forma de ampliar o entendimento acerca de conceitos complexos ou de difícil abstração. Ou seja, seu design é centrado, antes de tudo, na necessidade de traduzir visualmente a informação e, por isso, seu processo é dado em uma série de passos que dependem de variáveis dentro da gestão do projeto (figura 5):

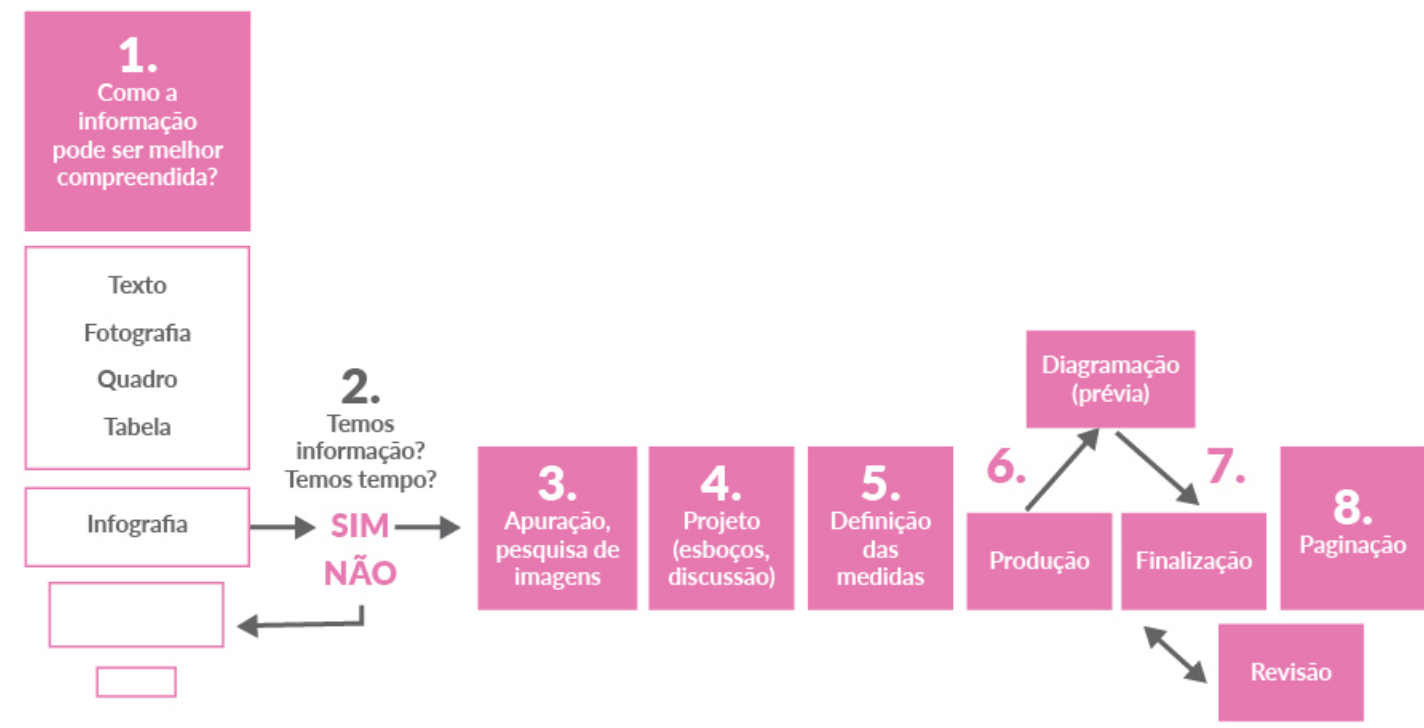

Figura 5 - Processo de design de infográficos jornalísticos de Moraes (2013) - adaptado pelo autor. 
Embora não possa ser considerado necessariamente uma evolução do processo de Aragão e Carvalho, a sequência de procedimentos trazida por Moraes nos deixa essa característica marcante da infografia, que é a valorização da informação e dos melhores meios para apresentá-la. O que ocorre no jornalismo é aplicável em outros meios nos quais a visualização da informação desempenha um papel central - a educação é um deles.

\section{EDUCAÇÃO À DISTÂNCIA E O DESIGN}

A Educação à Distância (EAD) é uma forma alternativa de aprendizagem: definida inicialmente conforme o Decreto 5.622 do Ministério da Educação e, hoje, com o objetivo de estabelecer diretrizes nacionais para a oferta de programas e cursos superiores na modalidade de educação à distância, tendo sua definição reformulada de acordo com a resolução CNE/CES 1/2016 trata-se de:

“(...) modalidade educacional na qual a mediação didático-pedagógica, nos processos
de ensino e aprendizagem, ocorre com a utilização de meios e tecnologias de
informação e comunicação, com pessoal qualificado, políticas de acesso,
acompanhamento e avaliação compatíveis, entre outros, de modo que se propicie,
ainda, maior articulação e efetiva interação e complementaridade entre a
presencialidade e a virtualidade "real”, o local e o global, a subjetividade e a
participação democrática nos processos de ensino e aprendizagem em rede,
envolvendo estudantes e profissionais da educação (professores, tutores e gestores),
que desenvolvem atividades educativas em lugares e/ou tempos diversos." (MEC,
2016)

O decreto prevê a EaD como multimidática e não tendo um modelo único de implementação, porém estando atrelada a algumas diretrizes para seu reconhecimento dentro de um padrão de qualidade. Dentre essas diretrizes, destacam-se:

a) a caracterização de EaD visando instruir os sistemas de ensino;

b) o estabelecimento de preponderância da avaliação presencial dos estudantes em relação às avaliações feitas a distância;

c) maior explicitação de critérios para o credenciamento no documento do plano de desenvolvimento institucional (PDI), principalmente em relação aos pólos descentralizados de atendimento ao estudante;

d) mecanismos para coibir abusos, como a oferta desmesurada do número de vagas na educação superior, desvinculada da previsão de condições adequadas;

e) permissão de estabelecimento de regime de colaboração e cooperação entre os Conselhos Estaduais e Conselho Nacional de Educação e diferentes esferas administrativas para: troca de informações supervisão compartilhada; unificação de normas; padronização de procedimentos e articulação de agentes;

f) previsão do atendimento de pessoa com deficiência;

g) institucionalização de documento oficial com Referenciais de Qualidade 2 para a educação a distância (MEC, 2005).

Segundo o documento de Referenciais de Qualidade para o ensino à Distância (MEC, 2007), o qual foi elaborado com a opinião de especialistas do setor, devem estar 
integralmente expressos no Projeto Político Pedagógico de um curso na modalidade a distância os seguintes tópicos: (i) Concepção de educação e currículo no processo de ensino e aprendizagem; (ii) Sistemas de Comunicação; (iii) Material didático; (iv) Avaliação; (v) Equipe multidisciplinar; (vi) Infra-estrutura de apoio; (vii) Gestão Acadêmico-Administrativa; (viii) Sustentabilidade financeira.

No tangente às competências do design gráfico, cabe ressaltar que o item (iii) Material didático - incorpora em sua definição a premissa de uma estrutura multidisciplinar na equipe responsável dentro do curso de educação a distância, que, de acordo com o documento de Referenciais de Qualidade, deve conceber e disponibilizar diferentes mídias integradas "explorando a convergência e integração entre materiais impressos, radiofônicos, televisivos, de informática, de videoconferências e teleconferências, dentre outros" (MEC, 2007). A adoção de tais canais, entretanto, deve estar em consonância com a realidade da sede e do(s) polo(s) do curso oferecido (MEC, 2016, Resolução CNE/CES 1/2016, Art. 3, parágrafo 5).

A educação à distância vem crescendo com rapidez no Brasil: já em 2004, estimava-se que meio milhão de pessoas estavam envolvidas no e-learning (Cavalcanti, 2012). Várias instituições de Ensino Superior (IES) vem aderindo à tendencia e disponibilizando diferentes cursos na modalidade. De acordo com a ABED - Associação Brasileira de Educação à Distância, 197 instituições de Ensino Superior ofereciam cursos nessa modalidade em 2009.

Um dos fatores que possibilita a abrangência dos cursos e a facilidade de acesso são os AVAs - Ambientes Virtuais de Aprendizagem. Comunidades de aprendizagem on-line são espaços nos quais professores e alunos trabalham e se sentem juntos no processo de aprendizagem, com um objetivo comum (Palloff, Pratt e Rapp 2000 APUD Cavalcanti, 2012). Segundo Franco et al. (2003), os primeiros projetos de construção de ambientes virtuais de aprendizagem destinados à educação iniciaram-se em meados da década de 1990, graças à evolução da internet e seu acesso através de navegadores. Segundo os autores, existem dois tipos de AVA:

"O primeiro tipo foi desenvolvido com base em um servidor web, utilizando sistemas abertos ou distribuídos, livremente, na internet. O segundo tipo se constitui em sistemas que funcionam em uma plataforma chamada proprietária, na qual a empresa que construiu o ambiente promove o seu desenvolvimento e controla a sua venda" (FRANCO et al., 2003:344)

Cavalcanti (2012) ressalta a importância do designer dentro do desenvolvimento, manutenção e abastecimento dos AVAs, interpretando seu extenso uso dentro da EaD como um mercado em ascensão para designers instrucionais, pedagogos, e outros profissionais atrelados ao processo. Isso vai de encontro também com o que comentava Ainsworth (2008) em relação ao uso de materiais gráficos na aprendizagem de conceitos científicos como um elemento potencialmente auxiliador e a infografia, sobretudo a animada, como uma indispensável ferramenta de apoio em materiais educacionais. 


\section{INFOGRAFIA NA EDUCAÇÃO À DISTÂNCIA}

Tendo posicionado a infografia como pertencente ao grupo de materiais com potencial de uso pela educação, pode-se encontrar vários exemplos do emprego destas em conteúdos didáticos atualmente em utilização na educação à distância.

Pessoa e Maia (2015) propõem que "a infografia pode atuar como estratégia complementar de ensino principalmente no contexto da interatividade". Segundo eles, não é tarefa do docente ou do produtor de conteúdo a tarefa da tradução visual das informações, entretanto, a possibilidade desse recurso não pode nunca ser descartada. O infográfico, ainda segundo Pessoa e Maia, permeia todos os tipos de linguagem disponíveis nos meios digitais, mas não deve ser considerado como solução final, já que serve para complementar a informação e fornecer subsídios para um melhor entendimento dos assuntos.

A decisão pelo uso de materiais infográficos deve obedecer a gestão dos materiais didáticos da EaD que, por sua vez, é baseada, antes de tudo, na modalidade de ensino (Peters, 2001). Conforme Da Silva (2003), alguns elementos da educação convencional transformam-se no contexto da EaD: um exemplo é o professor, agora "substituído" pela função de conteudista. Segundo o autor, o papel do conteudista é facilitar e orientar o processo educacional, selecionando fontes e atuando como um parceiro no processo de construção do conhecimento. Ele trabalha com outros profissionais no processo de criação e gerenciamento do conteúdo dos cursos (figura $6)$.

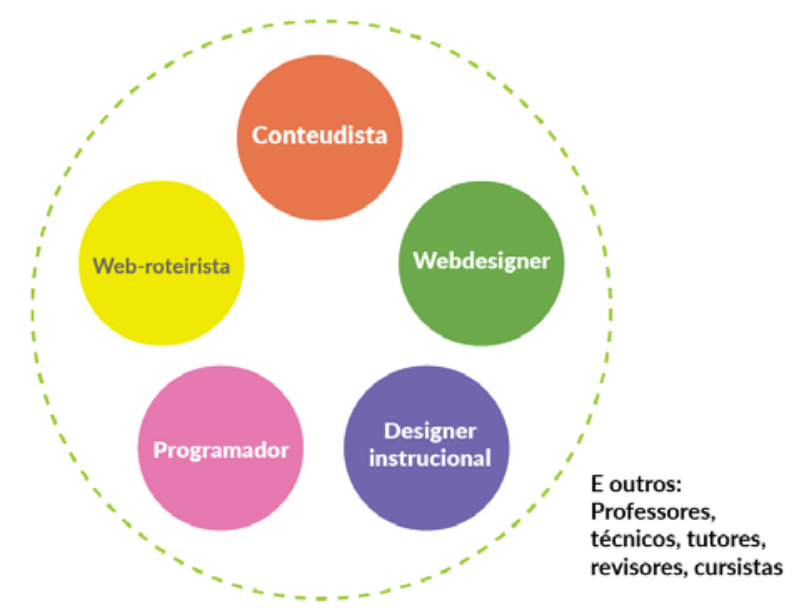

Figura 6 - Corpo de profissionais envolvidos na produção de conteúdo para educação à distância, de acordo com Da Silva (2003) - adaptado pelo autor.

A cada um desses profissionais, segundo Da Silva, atribuem-se estrategicamente as seguintes funções:

- Conteudista: cria e seleciona conteúdos, normalmente na forma de textos. Prepara o programa do curso;

- Web-roteirista: articula o conteúdo por meio de um roteiro. Para isso, utiliza ferramentas de linguagem (multimídia, hipertextos etc);

- Web-designer: desenvolve o roteiro, conferindo a ele qualidades visuais/estéticas; 
- Programador: desenvolve o AVA, desenvolve a interface, gerencia arquivos e o banco de dados;

- Designer instrucional: avalia os processos de construção e uso do curso. Analisa as necessidades e seleciona tecnologias de acordo com o contexto dos cursistas. Pode atuar também como o gestor do projeto.

Da Silva ainda propõe que a forma de interação entre os profissionais envolvidos no processo - a "articulação de saberes" - pode variar de três formas:

- Multidisciplinar: embora haja a participação de diferentes atores na produção dos saberes, não há cooperação entre eles e o conteúdo é produzido de forma justaposta: cada disciplina contribui com sua parte sem contextualização;

- Pluridisciplinar: ocorre uma justaposição de conteúdos, porém organizada de forma hierárquica e com a possibilidade de interferência do trabalho de um ator sobre o outro. Ocorre a cooperação, mas não a coordenação intencional dos vínculos;

- Interdisciplinar: ocorre o intercâmbio e enriquecimento mútuo na produção do conhecimento - cada disciplina envolvida passa a depender da outra e os conteúdos são articulados de modo coletivo.

Vale lembrar que os atores e as abordagens disciplinares envolvem a criação e gerenciamento do conteúdo como um todo. Faz-se, portanto, necessário um adendo à possível concepção de um processo de design de infográficos voltado ao contexto da educação à distância considerando o uso de tais peças gráficas como conteúdo educativo.

\subsection{Proposta de processo de design de infográfico para a educação à distância \\ Conforme os processos apresentados ao longo do presente estudo, podemos} inferir algumas diretrizes para a concepção de um processo de design de infográficos que atenda tanto às bases da infografia de qualidade quanto possua também uma configuração condizente com o contexto digital da educação à distância. São elas:

- Requisitos de escopo: disponibilidade de tempo, acesso ao conteúdo, disponibilidade de espaço e viabilidade dos meios de produção e reprodução;

- Requisitos informacionais: avaliação do propósito de uso, obtenção de dados sobre os usuários, adequação ao roteiro do curso;

- Requisitos formais: avaliação de peças similares, definição do formato (explicativo, exploratório ou historiográfico), definição midiática (animação, interação), elaboração da arquitetura da informação;

- Requisitos estéticos: definição do estilo visual, definição das dimensões, funcionalidades (programação), elaboração dos elementos da linguagem visual a serem utilizados, adequação da linguagem gráfica;

- Requisitos de publicação: inclusão de revisão e acabamento.

Tomando como base esses requisitos, propõe-se o processo de design descrito na figura 7: 


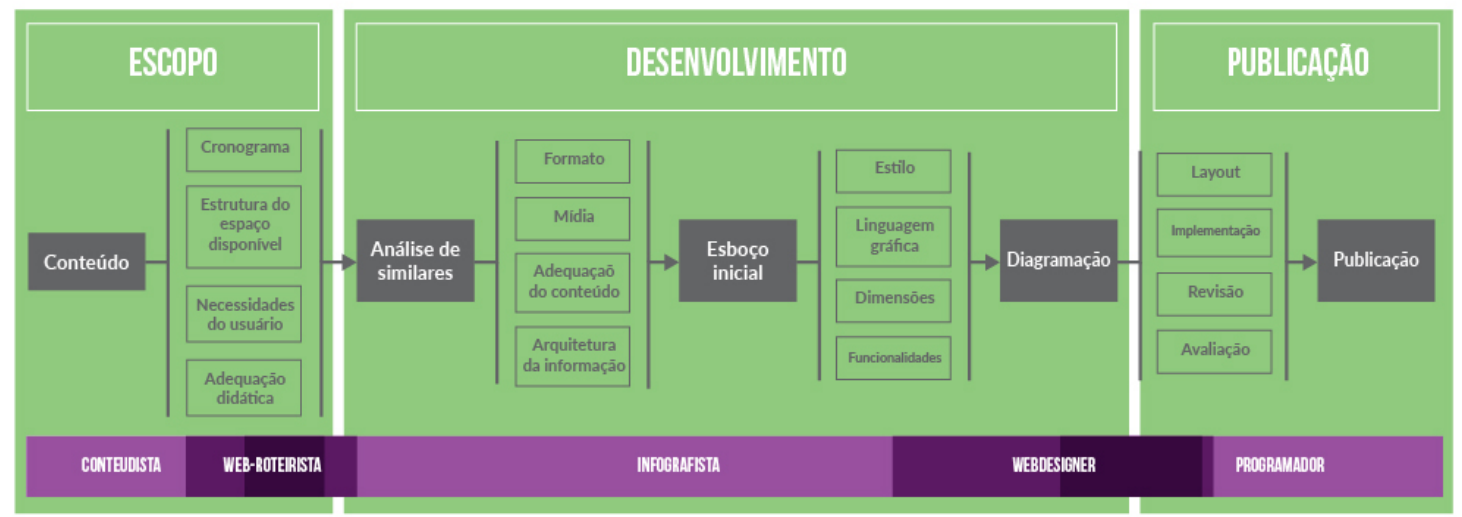

Figura 7 - Proposta de processo de design de infográficos para ambientes virtuais de educação (elaborado pelo autor).

O que se propõe é um processo dividido em três etapas: escopo, desenvolvimento e publicação. $\mathrm{Na}$ fase de escopo, as características projetuais são definidas: orçamento, espaço disponível, necessidades do usuário e adequação didática. Na fase seguinte, ocorre o desenvolvimento da peça gráfica, que começa com uma análise de similares cujos resultados se desdobram na definição do formato, da mídia e da arquitetura da informação a ser representada. Sugere-se que adequações do conteúdo sejam feitas nessa etapa se necessário. A produção segue com um esboço inicial do infográfico onde já se veem o estilo adotado (ilustração, fotografia etc), a linguagem gráfica (retórica, elementos visuais), as dimensões do infográfico e as funcionalidades caso interativo seja. A diagramação segue fazendo a ponte com a etapa final de publicação, na qual ocorre a implementação do conteúdo, a revisão e a avaliação do resultado perante os objetivos iniciais.

Além das tarefas, cada ator da criação e conteúdo na educação à distância aparece como responsável em uma abordagem interdisciplinar. O conteudista auxilia o web-roteirista nas definições do escopo. Também atua antes do desenvolvimento o infografista, um novo ator sugerido pelo processo, já que seria o responsável pela detenção das capacidades de criação infográfica. Esse novo ator é responsável pelo desenvolvimento e atua juntamente com o webdesigner e o programador nas etapas iniciais de publicação e ajustes do layout.

O processo foi construído com características dos processos de design apresentados anteriormente. Do processo de Frascara (2004), por exemplo, a definição do problema converte-se nas ramificações das tarefas da etapa de escopo do projeto. A preocupação retórica de Spinillo (2000) é vista na etapa de desenvolvimento, na tarefa de definição da linguagem gráfica pelo infografista. A participação do usuário também aparece - tanto na etapa de escopo quanto na avaliação final.

\section{CONSIDERAÇÕES FINAIS}

O presente artigo visava demonstrar a possibilidade da elaboração de um processo de design específico para a produção de infográficos voltados à complementação de conteúdo para educação a distância. Acredita-se que a infografia é uma poderosa ferramenta para auxiliar a compreensão de assuntos complexos. 
Para este fim, a infografia foi apresentada, desde sua definição até sua configuração atual como conceito dentro do design da informação. Além disso, ressaltou-se seu potencial além do uso jornalístico. Maneiras de visualizar processos de design pertinentes à infografia foram apresentados na sequência. A área da educação à distância foi igualmente abordada, ressaltando seu crescimento no Brasil. A criação de conteúdo para essa modalidade educacional apresenta um grupo de atores específicos cujos papéis se configuram conforme a estratégia disciplinar adotada.

Por fim, apresentou-se uma proposta de processo de design baseado em requisitos obtidos do estudo bibliográfico. Acredita-se que esse processo pode ser tanto uma ferramenta para infografistas que estejam atuando na área quanto para estudiosos que possam vir a discutir suas etapas e procedimentos em estudos futuros, visando aperfeiçoar o método e amplificar a possibilidade do uso da infografia em outras oportunidades de transmissão do conhecimento.

\section{REFERÊNCIAS}

AINSWORTH, Shaaron. The educational value of multiple-representations when learning complex scientific concepts. Visualization: Theory and practice in science education. Springer Netherlands, 2008. p. 191-208.

ANDRADE, Rafael Castro. Infográficos animados e interativos em saúde: Um estudo sobre a compreensão de notícias. Dissertação (Mestrado em Design). Universidade Federal do Paraná, Curitiba, 2014.

BRASIL . Referenciais de Qualidade para Educação Superior à Distância. Ministério da Educação, Secretaria de Educação à Distância, 2007.

BRASIL. Resolução CNE/CES 1/2016. Diário Oficial da União, Brasília, 14 de março de 2016, Seção1, págs. 23-24.

CENTRO BRASIL DESIGN (CBD). O que você quer para a sua empresa?: como inovar pelo design. Cartilha. S.d.

CARVALHO, Juliana; ARAGÃO, Isabella. Infografia: Conceito e Prática. InfoDesignRevista Brasileira de Design da Informação, v. 9, n. 3, 2013. P. 160-177.

CAVALCANTI, Carolina Magalhães Costa. Tendências e Possibilidades da Educação a Distancia como modalidade de ensino. (2012).

DA SILVA, Marco Antônio. Educação online: teorias, práticas, legislação, formação corporativa. Edicoes Loyola, 2003.

FRANCO, Marcelo Araújo; CORDEIRO, Luciana Meneghel; CASTILLO, Renata A. Fonseca. $O$ ambiente virtual de aprendizagem e sua incorporação na Unicamp. Educação e Pesquisa, v. 29, n. 2, 2003. P. 341-353.

FRASCARA, Jorge. Communication design - principles, methods and practice. New York: Allworth Press, 2004.

GIL, Antonio Carlos. Como elaborar projetos de pesquisa. São Paulo, 2002.

GOODWIN, Kim. Designing for the digital age: how to create human-centered products and services. Indianapolis: Wiley Publishing, 2009. 
LAKATOS, Eva Maria; MARCONI, Marina de Andrade. Fundamentos da metodologia científica. Altas, 2010.

LIMA, Ricardo Cunha. 0 que é infografia jornalística? Revista InfoDesign v. 12, n. 1, 2015. P. 111-127.

MIRANDA, Fabiano de. Animação e interação na infografia jornalística: Uma abordagem do Design da Informação. Dissertação (Mestrado em Design). Universidade Federal do Paraná, Curitiba, 2013.

MORAES, Ary. Infografia: história e projeto. São Paulo: Blucher (2013).

PESSOA, Alberto Ricardo; MAIA, Gisele Gomes. A infografia como recurso didático na Educação à Distância. Temática, v. 8, n. 5, 2015.

PETERS, Otto. Didática do Ensino a Distância. São Leopoldo,RS : UNISINOS, 2001. PROJECT MANAGEMENT INSTITUTE. A Guide to the Project Management Body of Knowledge - PMBOK. Pennsylvania, EUA. 2000.

RAJAMANICKAM, Venkatesh. Infographics seminar handout. Seminars on Infographic Design, National Institute of Design, Ahmedabad, and the Industrial Design Centre, Indian Institute of Technology, Bombay. 2005.

ROCHA, Heloísa Vieira; BARANAUSKAS, Maria Cecília Calani. Design e avaliação de interfaces humano-computador. Campinas: UNICAMP, 2003.

SCHMITT, V. A Infografia Jornalística na Ciência e Tecnologia: um Experimento com Estudantes de Jornalismo da Universidade Federal de Santa Catarina. Dissertação de Mestrado em Engenharia e Gestão do Conhecimento. Florianópolis: Universidade Federal de Santa Catarina. 2006.

SPINILLO, Carla Galvão. An analytical approach to procedural pictorial sequences. Tese de Doutorado (PhD) - Department of Typography \& Graphic Communication, The University of Reading. Reino Unido, 2000.

TWYMAN, Michael. A schema for the study of graphic language (tutorial paper). Processing of visible language. Springer US, 1979. 117-150.

\section{AUTORES}

Bolívar Teston de Escobar é mestrando no programa de pós graduação em design da Universidade Federal do Paraná (Sistemas da Informação). Bolsista CAPES-CNPQ.

Carla Galvão Spinillo é doutora em Typography Graphic Communication - University of Reading, Inglaterra. Pós-doutorado na University of Avans, Holanda. Atualmente é professora adjunto do PPGDesign da UFPR. 